\title{
Sustainable Development: A Quantitative Analysis Regarding the Impact of Resource Rents on State Welfare from 2002 to 2017
}

\author{
https://doi.org/10.21272/sec.4(4).119-131.2020. \\ Marcel Biewendt, ORCID: https://orcid.org/0000-0002-3410-7995 \\ PhD Candidate in Management \& Organisational Sciences, Kaposvár University, Hungary; Member of \\ Executive Board and Chief Operating Officer of IDA Institute at University of Applied Science Aachen, \\ Germany
}

\begin{abstract}
This paper uses a quantitative analysis to examine the interdependence and impact of resource rents on socioeconomic development from 2002 to 2017. Nigeria and Norway have been chosen as reference countries due to their abundance of natural resources by similar economic performance, while the ranking in the Human Development Index differs dramatically. As the Human Development Index provides insight into a country's cultural and socio-economic characteristics and development in addition to economic indicators, it allows a comparison of the two countries. The hypothesis presented and discussed in this paper was researched before. A qualitative research approach was used in the author's master's thesis "The Human Development Index (HDI) as a Reflection of Resource Abundance (using Nigeria and Norway as a case study)" in 2018. The management of scarce resources is an important aspect in the development of modern countries and those on the threshold of becoming industrialised nations. The effects of a mistaken resource management are not only of a purely economic nature but also of a social and socio-economic nature.

In order to present a partial aspect of these dependencies and influences this paper uses a quantitative analysis to examine the interdependence and impact of resource rents on socio-economic development from 2002 to 2017. Nigeria and Norway have been chosen as reference countries due to their abundance of natural resources by similar economic performance, while the ranking in the Human Development Index differs significantly. As the Human Development Index provides insight into a country's cultural and socio-economic characteristics and development in addition to economic indicators, it allows a comparison of the two countries.
\end{abstract}

This paper found out in a holistic perspective that (not or poorly managed) resource wealth in itself has a negative impact on socio-economic development and significantly reduces the productivity of the citizens of a state.

This is expressed in particular for the years 2002 till 2017 in a negative correlation of GDP per capita and HDI value with the share respectively the size of resources in the GDP of a country.

Keywords: Human Development Index, sustainability, resource abundance, socio-economic welfare.

JEL Classification: O13.

This work is licensed under a Creative Commons Attribution 4.0 International License.

Cite as: Biewendt, M. (2020). Sustainable Development: A Quantitative Analysis Regarding the Impact of Resource Rents on State Welfare from 2002 to 2017. SocioEconomic Challenges, 4(4), 119-131.

https://doi.org/10.21272/sec.4(4).119-131.2020.

(C) The Author, 2020. This article is published with open access at Sumy State University.

\section{Introduction}

The Human Development Index (HDI) gained more and more relevance over the past decades. Since GDP does not adequately reflect the economic and especially the social development of a country (Mohajan, 2015), indices such as the Human Development Index, but also alternative indices such as the Happy Planet Index are becoming increasingly important (Gallardo, 2009). Norway and Nigeria, which have similar economic performances 
(current difference of 9\% in GDP), are examples of this (Worldbank, 2020). Even tough GDP claims that both perform similar in economic terms, the reality of life for the citizens of these two countries is very different. Globally, there are several resource-rich countries, but they have very different living standards. Besides Nigeria and Norway these include among others Venezuela, the United States of America, Saudi Arabia, Australia, Brazil, China, Canada and Russia. It can therefore be stated that resource-rich countries are not only among the richest but also among the poorest nations in the world (Torvik, 2009).

Table 4. Comparison of GDP (2018), GDP per Capita (2018), HDI value (2019) and Ressource-Rents (2017) among selected resource rich countries

\begin{tabular}{|c|c|c|c|c|}
\hline Country & $\begin{array}{c}\text { GDP in trillion } \\
\text { (constant 2017 PPP } \\
\text { USD) }\end{array}$ & $\begin{array}{c}\text { GDP per Capita } \\
\text { (constant 2017 PPP USD) }\end{array}$ & $\begin{array}{c}\text { Resources rents in } \\
\text { \% of GDP }\end{array}$ & $\begin{array}{c}\text { HDI Index in } \\
\text { points }\end{array}$ \\
\hline USA & 20.523 & 62,527 & 00.50 & 0.920 \\
\hline China & $\mathbf{2 2 . 5 2 6}$ & 16,117 & 01.50 & 0.758 \\
\hline Brazil & 3.092 & 14,652 & 03.50 & 0.761 \\
\hline Canada & 1.843 & 49,031 & 01.70 & 0.922 \\
\hline Russia & 3.968 & 27,044 & 10.70 & 0.824 \\
\hline Australia & 1.262 & 49,756 & 07.20 & 0.938 \\
\hline Saudi-Arabia & 1.609 & 46,962 & $\mathbf{2 3 . 8}$ & 0.857 \\
\hline Congo (Dem. Rep.) & 0.095 & 1,098 & 11.80 & 0.726 \\
\hline Norway & 0.340 & $\mathbf{6 3 , 6 3 3}$ & 05.90 & $\mathbf{0 . 9 5 4}$ \\
\hline Nigeria & 1.032 & 5,135 & 08.70 & 0.534 \\
\hline
\end{tabular}

Source: (Worldbank, 2020; United Nations, Human Development Reports, 2020).

Table 1 compares different economic values on a country basis. It is noticeable that countries with a much lower GDP can have a much better HDI value (compare e.g. Australia and USA). Furthermore, one has to pay attention to how much of the GDP is generated by revenues from the sale of ressources. Here, Saudi Arabia leads the selected countries with $23.8 \%$, followed by Venezuela with $11.8 \%$ and Russia with $10.7 \%$. In other words, some of these countries generate more than a fifth of their GDP through the exploitation and sale or export of natural ressources $^{2}$.

It is questionable whether such a high share of GDP has an impact on the development (social, economic and ecological) of a country and to what degree it influences the HDI ranking. A possible answer to this question is the so-called Rentier State Model which was first developed in its modern version by Hossein Mahdavy in the 1970's (Mahdavy, 1970) and later on by Hazem El Beblawi and Giacomo Luciani at the end of the 1980's (Beblawi \& Luciani, 1987). Moreover, the ecological price of economic growth is especially under today's public awareness a key point to evaluate when discussing the reciprocal effects of GDP growth and resource welfare and usage. A trend is, that countries tend to reach the so called "strong decoupling" of the two variables, whereas the average ecological footprint intensity of countries have improved significantly in general (Tóth, Szigeti, \& Szabo, 2016). Beside natural exploitation of resources like gas, oil, coal etc. resources like agricultural products from the agricultural industry of a nation can be used as an identifier of the specific productivity performance of a country, probably impacting the overall HDI score. A comparison towards that has been made by Baráth and Fertő in 2016 concluding that European states generally converging in that case (Baráth \& Fertö, 2016). Probably meaning, that a strong and reciprocal cooperation between countries stabilises and equalises productivity differences.

Taking a broad range of the several theoretical frameworks dealing with this question into account, the results from a qualitative research perspective showed, that the overall picture emerges that the hypothesis can be confirmed independently and by various literature sources, which correlate the placement in HDI ranking with a country's wealth of resources (Biewendt, The Human Development Index (HDI) as a Reflection of Resource Abundance (using Nigeria and Norway as a case study), 2018).

\footnotetext{
${ }^{2}$ Including oil rents, natural gas rents, coal rents (hard and soft), mineral rents, and forest rents
} 


\section{Research Methods}

The research derived here used qualitative analytical methods in preparation for the actual analysis by collecting and analysing secondary data. Primarily, however, quantitative primary data from the World Bank were used. These are supplemented by other credible online sources that were analysed with RStudio and, together with World Bank data, form the basis of the research presented here. Secondary data for qualitative and quantitative analysis were also collected from relevant literature sources such as journals, reports, books, relevant and credible newspapers, as well as from sources such as the World Trade Organization, the World Economic Forum and the United Nations. The data collected has been checked for consistency and reliability by comparison with other sources (Saunders, Lewis, \& Thornhill, Research Methods for Business Students (Fith edition), 2009). The analysis is consequently showing possible correlations, but is limited to three variables therefore not depicting the absolute reality. In absolute reality, there are significantly more factors and variables that influence the HDI value of a country, whereas this research may only present results based on the given model within a specific time frame.

\section{State of Affairs}

The Human Development Index is defined as follows: “... a measure for assessing progress in three basic dimensions of human development: a long and healthy life, access to knowledge and a decent standard of living" (United Nations, Human Development Reports, 2020). The Human Development Index has its origins in the work and research of the well-known economist Mahbub ul Haq which thrived to "...explore a new development paradigm whose central focus is on human well-being" (Mahbub, 1995). With his work "Reflections on Human Development", Mahbub ul Haq thus introduced a new way of looking at human development which, in contrast to previous approaches, also includes socio-economic characteristics in the assessment of a country's development.

Hence, the rentier state model uses socio-economic attributes as the basis of its approach, possibly showing a link between countries that are classified as rentier states and rated accordingly in the Human Development Index. It should be noted, however, that the Human Development Index is also only a model that reflects reality under certain aspects, thus simplifying reality in certain areas. The results, even if they are scientifically sound, therefore only represent an approximation of reality and should be viewed critically as such.

Over the decades, several studies have explored and analysed the impact of countries' resource wealth and the corresponding effect on economic growth. Beneath others Thorvaldur Glyfason wrote an essay with the title "Natural resources, education, and economic development" (Gylfason, 2001), Ragnar Torvik wrote a paper dealing with the question "Why do some resource abundant countries succeed while others do not?" (Ragnar, 2009), the authors Adebiyi Oyeyemi Omodadepo and Olomola Philip Akanni dealt with the topic "Oil wealth; meat in Norway, poison in Nigeria: An analysis of human capital as a transmission channel of resource curse" (Omodadepo \& Akanni, 2013). The ecological price of economic growth is another factor that must be considered, for instance the decoupling of ecological footprint and GDP growth. Reciprocal effects of resource welfare and a nation's economic growth may heavily impact the sustainable development of industry and production capacities when taking natural protection and sustainability into account (Tóth, Szigeti, \& Szabo, 2016) .

However, there are barely any studies on how the abundance of natural resources of a country that can be classified as a Rentier State affects the HDI ranking or how the two are related.

The aim of this article is therefore to quantitively analyse the significance of the HDI ranking in relation to countries classified as Rentier States by using Nigeria and Norway as reference countries. The objectives of this paper are also to research the relevant literature in the field of interest and to review the conceptual frameworks.

\section{Results and Discussion}

In the following chapter, the statistical analyses of Nigeria and Norway are presented. In their entirety, it is examined whether and what influence the share of resource rents in GDP and GDP per capita (in constant 2017 PPP US\$) has on the corresponding country-specific HDI value. The object GDP per capita was chosen as the 
test reference value. The HDI value of a country is influenced by the corresponding value of GDP per capita, since the latter is used as part of the calculation basis.

The following parameters, in the period 2002 to 2017, were examined:

\section{- $\quad$ HDI Value \\ - $\quad$ Share of Resource Rents of GDP \\ - $\quad$ GDP per Capita in constant 2017 PPP US\$}

First the results for Nigeria and then for Norway will be presented. The results are summarised, compared and evaluated in the corresponding conclusion. In addition to a graphical representation with an $\mathrm{AB}$ trend line and a polynomial trend line, the respective sub-hypotheses are checked by means of ANOVA. The data analysis carried out considers the three variables "HDI value", "GDP per capita in constant 2017 PPP-US\$" and "Resource rents as a percentage of GDP" on the basis of 30 properties (among the years and on average between 2002 and 2017 are considered. The comparison of the HDI value and GDP per capita serves as a test value, as the HDI value is also calculated by taking GDP per capita into account. A correlation is therefore imperative. However, it should be noted that the HDI value is calculated using the special indicator "PPP US\$ 2011" and not "PPP US\$ constant 2017 " as used in this analysis. The difference is marginal and has no impact on the result. It should also be noted that the information value is limited to the period analysed. When viewed over a longer period of time, results may vary. Especially as unforeseen influences and external factors not covered here influence the informative value. Above all, political decisions that take effect over a longer period of time, for example in the form of economic upheavals or extreme events such as wars, distort the picture. Particularly in Nigeria, with a very dynamic development in society, politics and lifestyle of the population, the results are therefore of limited informative value. The detailed analysis below shows possible correlations graphically and shows both a linear and a polynomial trend line for the case of Nigeria.

\section{Country Information of Nigeria}

With a total area of $923,768 \mathrm{~km}^{2}$, Nigeria is two and a half times the size of the Federal Republic of Germany $\left(357.385,71 \mathrm{~km}^{2}\right)$ and almost three times the size of Norway $\left(323.8021 \mathrm{~km}^{2}\right)$. The longest extension from west to east is $1,300 \mathrm{~km}$, from north to south $1,100 \mathrm{~km}$. The length of the coast is $853 \mathrm{~km}$. Oil and gas have been firstly found 1956 in Oloibiri and afterwards produced and exported since 1958 (OPEC, 2020).

The massive pollution and destruction of the environment still cost the lives of thousands of people, despite mass protests by the ethnic groups living there, i.e. in the Niger Delta (Odeyeme \& Ogunseitan, 1985) . The destruction of the environment and habitat in the Niger Delta as a result of oil production is described in detail in a report by Amnesty International (Amnesty-International, 2019).

Table 5. Key Indicators of Nigeria

\begin{tabular}{|c|c|c|c|c|c|}
\hline & $\begin{array}{c}\text { Life expectancy } \\
\text { at birth }\end{array}$ & $\begin{array}{c}\text { Expected years } \\
\text { of schooling }\end{array}$ & $\begin{array}{c}\text { GDP per Capita (constant 2017 } \\
\text { PPP USD) }\end{array}$ & $\begin{array}{c}\text { Resource rents } \\
\text { (\% of GDP) }\end{array}$ & HDI Value \\
\hline 1990 & 45.9 & 06.70 & 3,259 & $\mathbf{2 4 . 8 7}$ & \\
\hline 1995 & 45.9 & 07.20 & 2,901 & 20.51 & \\
\hline 2000 & 46.3 & 08.00 & 2,977 & 23.66 & \\
\hline 2005 & 48.3 & 09.00 & 3,997 & 20.61 & 0.467 \\
\hline 2010 & 50.9 & 08.40 & 4,932 & 14.86 & 0.484 \\
\hline 2011 & 51.3 & 08.70 & 5,056 & 16.19 & 0.494 \\
\hline 2012 & 51.8 & 08.90 & 5,131 & 12.89 & 0.512 \\
\hline 2013 & 52.2 & $\mathbf{1 0 . 0}$ & 5,329 & 10.32 & 0.519 \\
\hline 2014 & 52.7 & 09.80 & $\mathbf{5 , 5 1 6}$ & 05.06 & 0.524 \\
\hline 2015 & 53.1 & 09.70 & 5,514 & 04.86 & 0.527 \\
\hline 2016 & 53.5 & 09.50 & 5,284 & 04.40 & $\mathbf{0 . 5 3 3}$ \\
\hline 2017 & $\mathbf{5 4 . 0}$ & 09.70 & 5,190 & & \\
\hline
\end{tabular}

Source: (Worldbank, 2020; United Nations, Human Development Reports, 2020). 
Nigeria's GDP per capita increased according to Nigeria's 2020 HDI Report from 1990 until 2017 by 59.25 percent as seen in Table 2. Further Table 2 shows that the HDI value has increased from 2005 to 2017 by 14,13 percent, the life expectancy raised from 1990 to 2017 by 17,65 percent and the expected years of schooling in the same time by $44,78 \%$. No HDI value data are currently recorded for Nigeria for the years 1990 to 2004, whereas these years could not be included in the analysis (United Nations, Human Development Reports, 2020).

\section{Quantitative Analysis and Key Indicators of Nigerian Regression of Nigerian HDI Value and Share of} Resource Rents of GDP

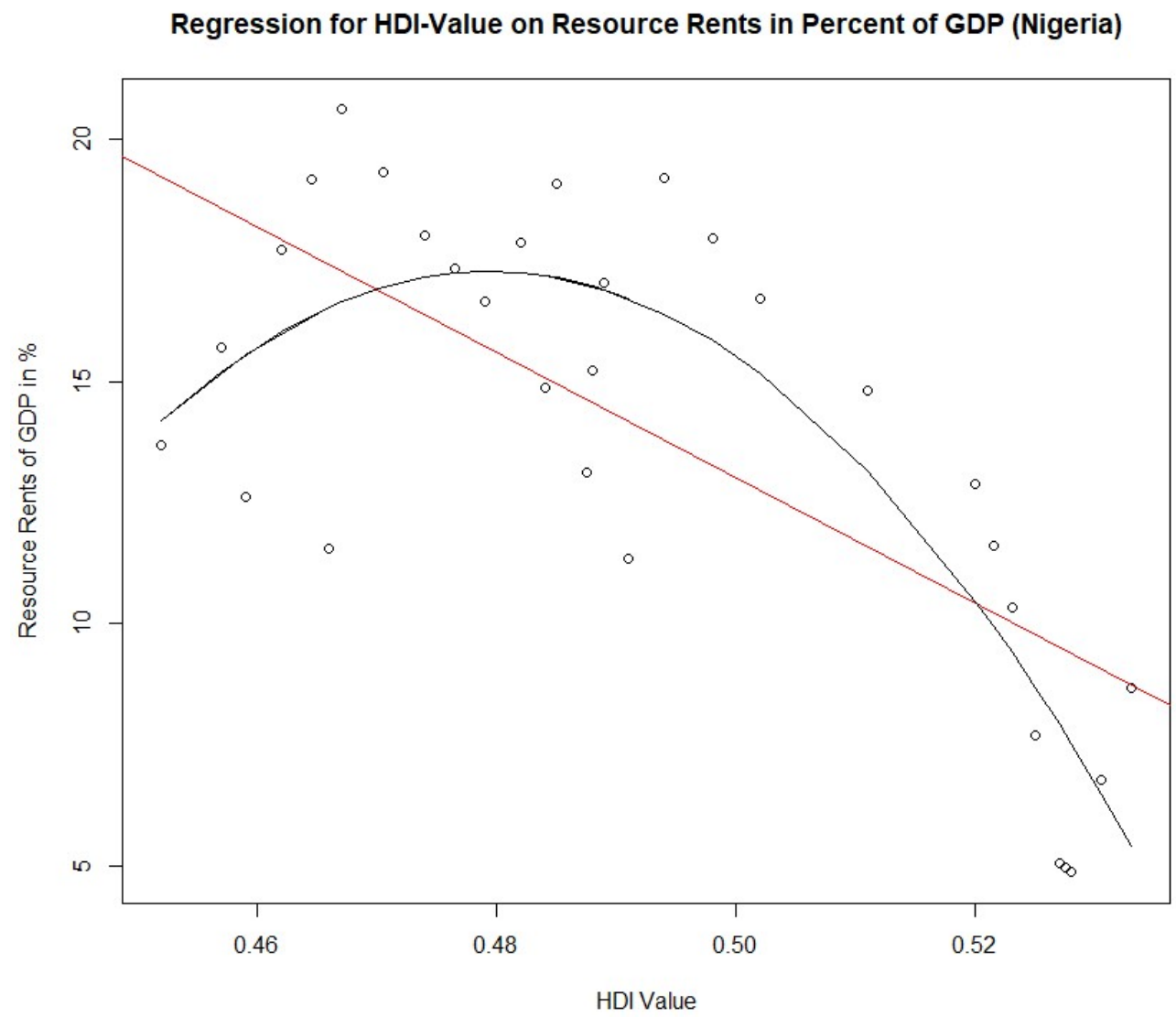

Figure 6. Regression \& linear (red) poynomal (black) trendline for Resource Rents in percentage of GDP to according HDI-Value of Nigeria for years 2002-2017* with linear regression line (red) and polynomal regression line (black).

Source: (Biewendt, Quantitative Analysis of Nigerian and Norwegian Parameters, 2020).

Figure 2 shows a graph showing resource rents as a percentage of Nigerian GDP on the $\mathrm{Y}$ axis and the Nigerian $\mathrm{HDI}$ value on the $\mathrm{X}$ axis. It shows a linear $\mathrm{AB}$ trend line and a polynomial trend line. The data collection period extends from 2002 to 2017. It can be seen that as the HDI value increases, the percentage of resource rents decreases, respectively the graph shows that the higher the percentage of resource rents, the lower the HDI value. Therefore, it can be concluded at this point that, based on the available data, countries that want to improve their HDI value should consider diversifying or reducing a GDP with a high percentage of resource rents.

\section{Regression of Nigerian GDP per Capita in constant 2017 PPP US\$ and HDI Value}




\section{Regression for HDI-Value \& GDP per Capita (Nigeria)}

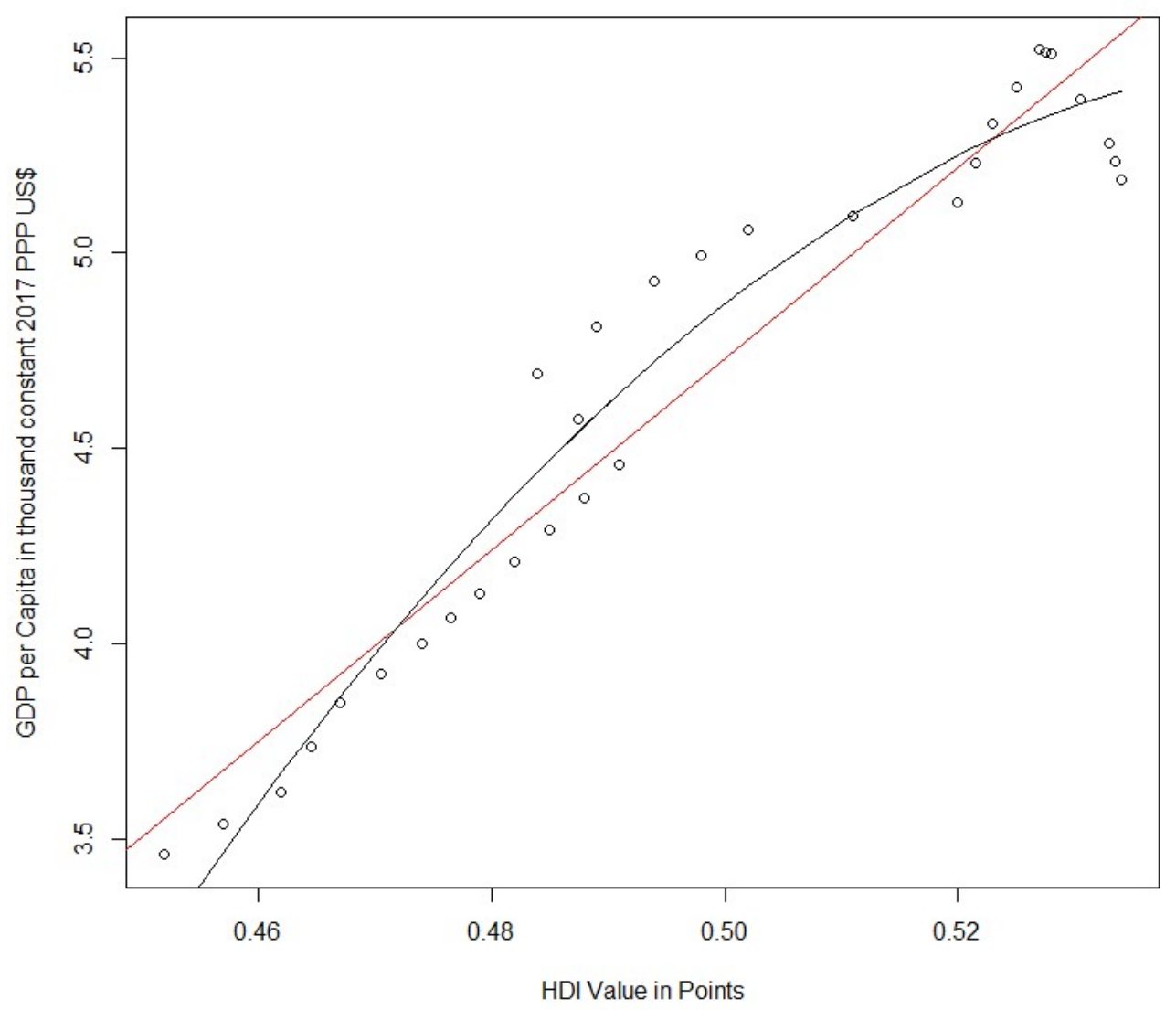

Figure 7. Regression \& linear (red) poynomal (black) trendline for HDI-Value to according GDP per

\section{Capita of Nigeria for years 2002-2017}

Source: (Biewendt, Quantitative Analysis of Nigerian and Norwegian Parameters, 2020)

Figure 3 shows a graph displaying Nigerian GDP per capita in constant 2017 PPP US\$ on the Y axis and Nigerian HDI Value on the $\mathrm{X}$ axis. Further a linear AB trend line and a polynomial trend line is shown. The data collection period is from 2002 to 2017 and shows that the higher the HDI value, the higher the GDP per capita, respectively the graph shows that the higher the GDP per capita, the higher the HDI value. Since the GDP per capita indicator is part of the HDI value (and is used here as a test value), there must be a correlation between the two values. A higher value of GDP per capita therefore "automatically" produces a better HDI value.

Regression of Nigerian Share of GDP Resource Rents and GDP per Capita in 2017 PPP US\$ 
Regression for GDP per Capita \& Share of Resource Rents (Nigeria)

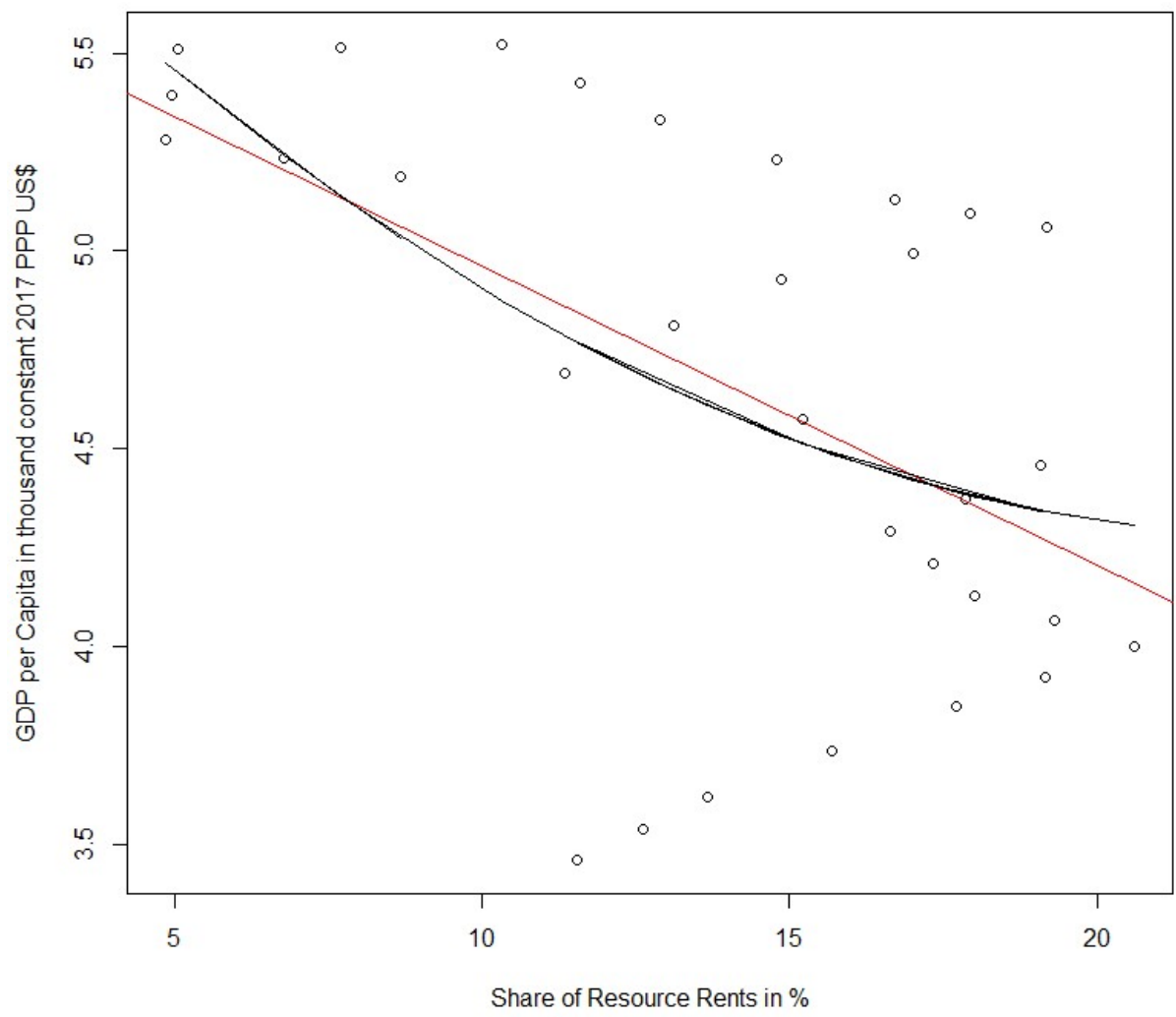

Figure 8: Regression \& linear (red) poynomal (black) trendline for Resource Rents in percentage of GDP according GDP per Capita in constant 2017 PPP US\$ of Nigeria for years 2002-2017

Source: (Biewendt, Quantitative Analysis of Nigerian and Norwegian Parameters, 2020).

Figure 4 shows a graph displaying Nigeria's resource rents as a percentage of GDP on the Y axis and Nigeria's GDP per capita on the $\mathrm{X}$ axis. It shows a linear $\mathrm{AB}$ trend line and a polynomial trend line. The $\mathrm{AB}$ trendline displays that with increasing Nigerian GDP per capita the percentage share of resource rents in Nigerian GDP decreases, respectively the graph indicates that the higher the percentage share of Nigerian resource rents in GDP, the lower the Nigerian GDP per capita. It thus indicates that even without the other factors of the HDI value, a direct negative impact on the economic productivity of citizens can be proven. Possible reasons for this are suggested in the author's qualitative study. (Biewendt, The Human Development Index (HDI) as a Reflection of Resource Abundance (using Nigeria and Norway as a case study), 2018).

\section{Country Information of Norway}

At $323.8021 \mathrm{~km}^{2}$, Norway is almost as large as Germany $\left(357.385,71 \mathrm{~km}^{2}\right)$ and a little bit bigger than Italy $\left(301.338 \mathrm{~km}^{2}\right)$ with a population of 5.305 .000 inhabitants. The length of the country is $1,572 \mathrm{~km}$ as the crow flies from Kristiansand in the south to Hammerfest near the North Cape. The border to Sweden is 1,619 km long, that to Finland $727 \mathrm{~km}$ and that to Russia $196 \mathrm{~km}$. Per capita income in Norway is one of the highest, as is in child benefit (Worldbank, 2020). In Norway, oil and gas have been produced mainly through offshore facilities since the early 1970s (Economics, 2020). Norway is one of the largest oil and gas exporters in the world. The deposits of the Norwegian state pension fund, established in 1996 and composed of revenues from the oil and gas business, have a market value of around $€ 1$ trillion (Norges-Bank, 2020). By adopting the "rule of action", the Norwegian 
government may withdraw a maximum of $3 \%$ of the capital stock from the fund for financing the state budget each year (Financial-Times, 2020).

Table 6. Key Indicators of Norway

\begin{tabular}{|l|c|c|c|c|c|}
\hline & $\begin{array}{c}\text { Life expectancy at } \\
\text { birth }\end{array}$ & $\begin{array}{c}\text { Expected years of } \\
\text { schooling }\end{array}$ & $\begin{array}{c}\text { GDP per Capita } \\
\text { (constant 2017 PPP } \\
\text { USD) }\end{array}$ & $\begin{array}{c}\text { Resource rents (\% } \\
\text { of GDP) }\end{array}$ & HDI Value \\
\hline 1990 & 76.50 & 14.00 & 41,406 & 07.67 & 00.85 \\
\hline 1995 & 77.70 & 15.60 & 48,407 & 04.98 & 00.88 \\
\hline 2000 & 78.7 & 17.50 & 56,137 & $\mathbf{1 1 . 8 6}$ & 00.92 \\
\hline 2005 & 79.9 & 17.50 & 60,798 & 10.53 & 00.93 \\
\hline 2010 & 81.00 & 17.50 & 60,290 & 08.91 & 0.94 \\
\hline 2011 & 81.30 & 17.60 & 60,097 & 10.99 & 00.94 \\
\hline 2012 & 81.45 & 17.50 & 60,916 & 10.38 & 00.94 \\
\hline 2013 & 81.75 & 17.70 & 60,806 & 08.86 & 00.95 \\
\hline 2014 & 82.10 & 17.70 & 61,308 & 7.94 & 00.95 \\
\hline 2015 & 82.30 & 17.80 & 61,895 & 05.33 & 00.95 \\
\hline 2016 & 82.41 & 18.00 & 62,010 & 04.13 & 00.95 \\
\hline 2017 & $\mathbf{8 2 . 5 1}$ & $\mathbf{1 8 . 1 0}$ & $\mathbf{6 2 , 9 4 0}$ & 05.93 & $\mathbf{0 0 . 9 5}$ \\
\hline
\end{tabular}

Source: (Worldbank, 2020; United Nations, Human Development Reports, 2020).

Norway's Gross Domestic Product per capita increased according to Norway's 2020 HDI Report from 1990 until 2017 by 52.01 percent as seen in Table 2. Further Table 2 shows that the HDI value has increased from 1990 to 2017 by 11,77 percent, the life expectancy raised from 1990 to 2017 by 7.86 percent and the expected years of schooling in the same time by 29.2 percent (United Nations, Human Development Reports, 2020).

Quantitative Analysis of Norwegian Key Indicators Regression for Norwegian Share of Resource Rents of GDP and HDI Value

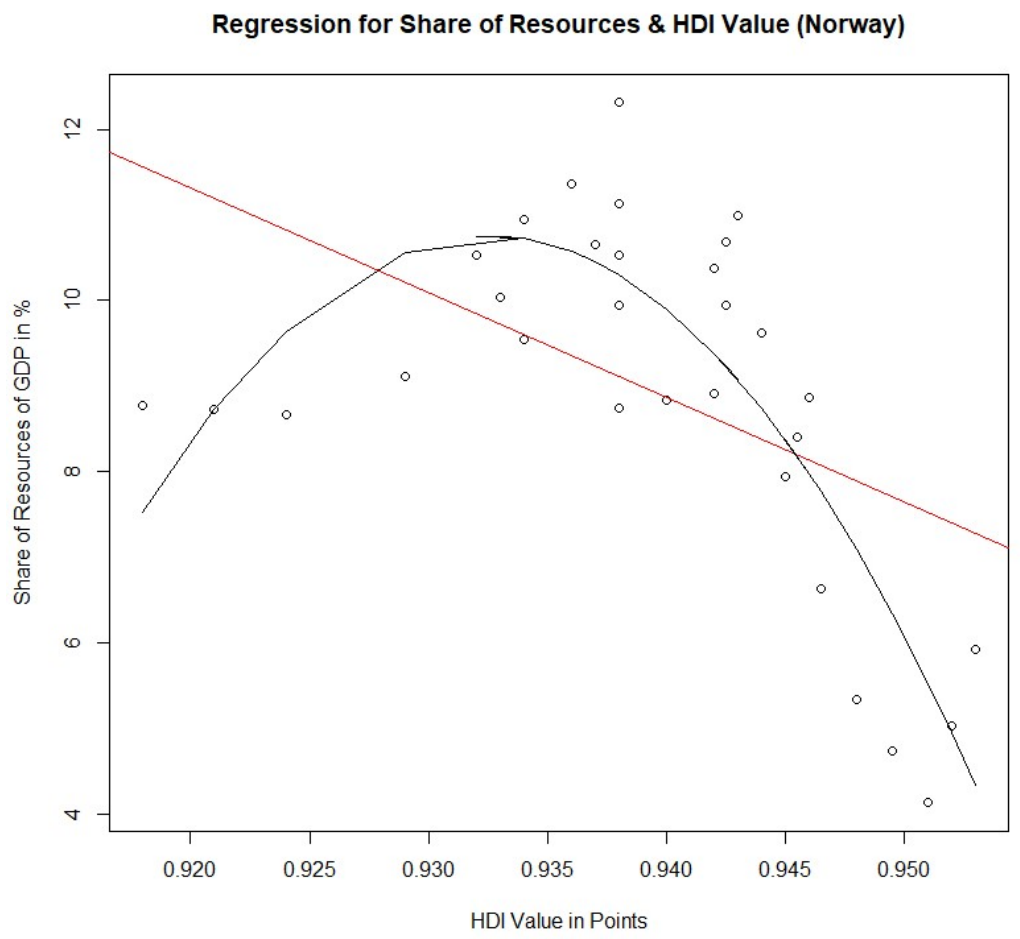

Figure 9. Regression \& linear (red) poynomial (black) trendline for Resource Rents in GDP in percentage 
to according HDI Value of Norway for years 2002-2017

Source: Biewendt, Quantitative Analysis of Nigerian and Norwegian Parameters (2020).

Figure 5 shows a plot graph displaying Norwegian share of resource rents of national GDP in percent on the Y axis and the Norwegian HDI-Value on the X-Axis. A linear AB trendline and a polynomial trendline are shown. The data collection period is from 2002 to 2017. It can be seen that with increasing HDI value the GDP per Capita increases, respectively the graph shows that the higher the GDP per Capita, the higher the HDI value.

Regression of Norwegian GDP per Capita in constant 2017 PPP US\$ and HDI Value

\section{Regression for GDP per Capita \& HDI Value (Norway)}

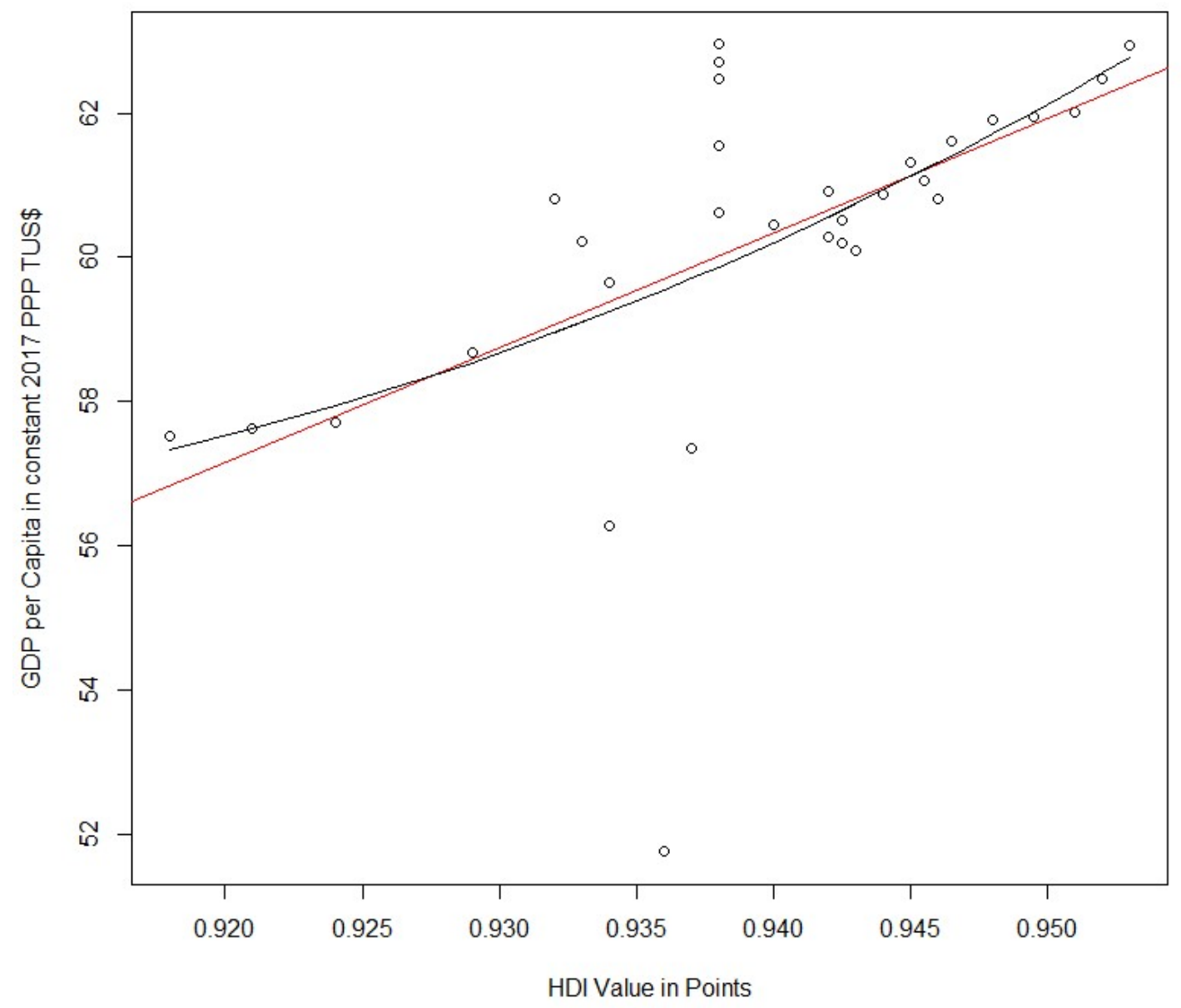

Figure 10. Regression \& linear (red) poynomal (black) trendline for HDI-Value to according GDP per Capita of Nigeria for years 2002-2017

Source: Biewendt, Quantitative Analysis of Nigerian and Norwegian Parameters (2020).

Figure 6 shows a plot graph displaying Norwegian GDP per Capita in constant 2017 PPP TUS\$ Y axis and the Norwegian HDI-Value in points on the X-Axis. A linear AB trendline and a polynomial trendline are shown. The data collection period is from 2002 to 2017. It can be seen that with increasing HDI value the GDP per Capita increases, respectively the graph shows that the higher the GDP per Capita, the higher the HDI value. 
Regression of Norwegian GDP per Capita in constant 2017 PPP US\$ and Share of Resources in Percent

\section{Regression for GDP per Capita \& Share of Resources in Percent (Norway)}

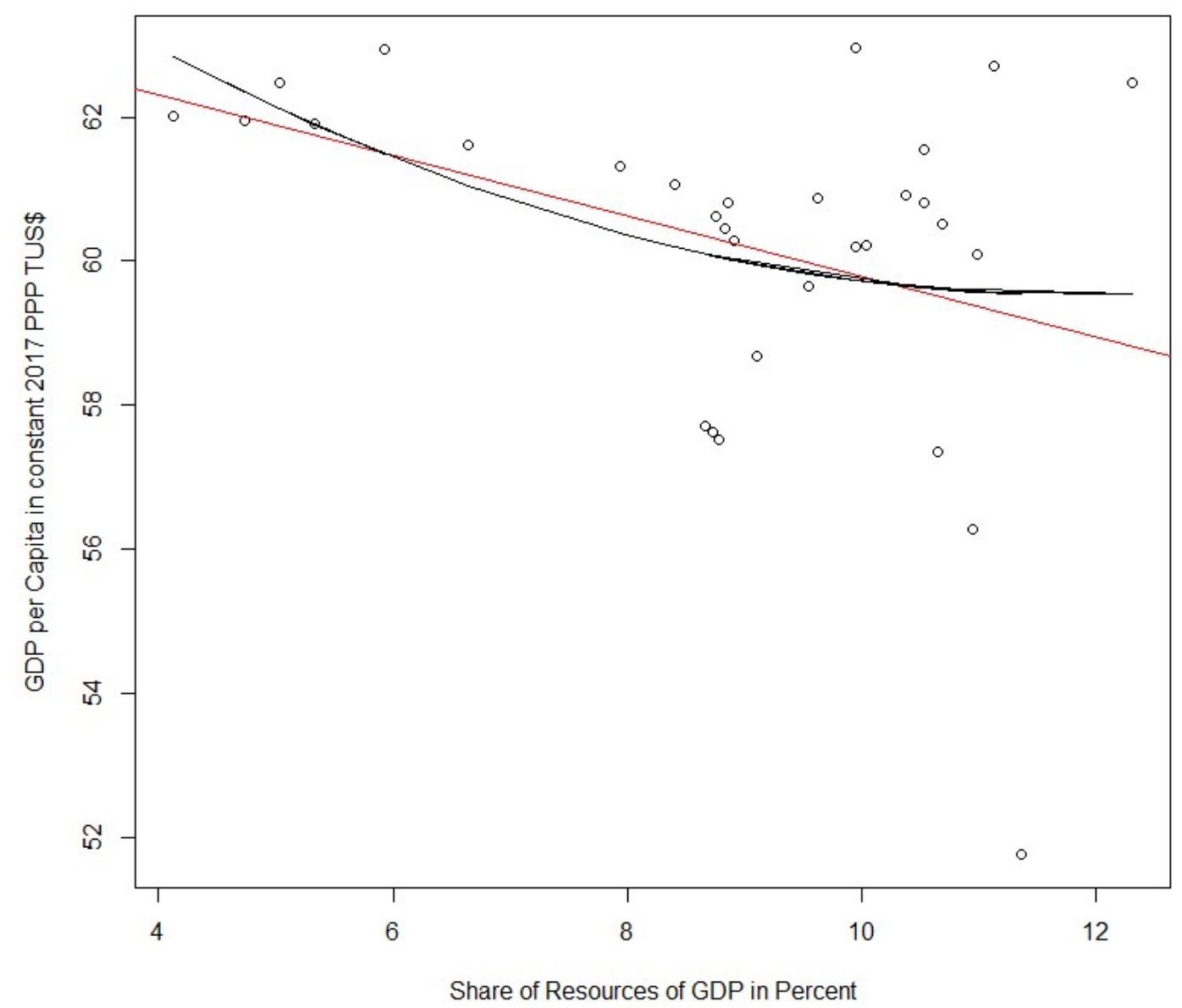

Figure 11. Regression \& linear (red) poynomal (black) trendline for Share of Resource Rents to according GDP per Capita of Nigeria for years 2002-2017

Source: Biewendt, Quantitative Analysis of Nigerian and Norwegian Parameters (2020).

Figure 7 shows a plot graph displaying Norwegian share of resource rents in GDP in percent on the Y axis and the Norwegian GDP per Capita on the X-Axis. A linear AB trendline and a polynomial trendline are shown. The data collection period is from 2002 to 2017. Analogous to the Nigerian analysis, the Norwegian model also shows that resource wealth has a negative, albeit less pronounced, influence on the individual productivity of citizens.

\section{Conclusion}

The literature review indicated that there are currently several approaches and theories for determining the general impact of resource wealth on the economic and social behaviour of a country. In any case, the influence of the rentier state construct or a country's wealth of natural resources on the corresponding HDI value has not been sufficiently researched yet.

An earlier executed qualitative research project by the author found that the current literature shows that resource wealth tends to have a negative impact on a country's socio-economic development. This is beneath others, due to an imbalance of dependence between the state and its citizens, which is decoupled, for example, by the rents 
generated by oil. In this paper a quantitative assessment was made of whether and to what extent the HDI value of a country correlates with the share of resource revenues in GDP. The analysis is able to point out that the null hypothesis that the share of resource revenues in GDP has no influence on the HDI value and thus on the overall socio-economic development in the countries studied can be rejected. A higher share therefore leads to a lower HDI value or to slower or less favourable development of the respective country due to a negative correlation.

An impact on the productivity of the individual citizen, expressed as GDP per capita, can also be demonstrated. Here, too, there is a negative correlation, indicating that resource wealth reduces individual productivity. It is noteworthy that this correlation is valid for both Nigeria and Norway for the observed period, even though national cultural and society strongly differs. However, since not all influencing factors are included in this analysis and the observation period is limited to 15 years, further research is needed to analyse and discuss these results from other perspectives, if necessary.

\section{Acknowledgement}

The author would like to convey his gratitude to Prof. Dr. Imre Fertő, Prof. Dr. Gergely Tóth and Prof. Dr. Martin Wolf for their very helpful and critical questions and comments during the preparation of this document.

Funding: self-funded.

Author contribution: conceptualization, Marcel Biewendt; data curation, Marcel Biewendt; formal analysis, Marcel Biewendt; funding acquisition, Marcel Biewendt; investigation, Marcel Biewendt; methodology, Marcel Biewendt; project administration, Marcel Biewendt; resources, Marcel Biewendt; software, Marcel Biewendt; supervision, Marcel Biewendt; validation, Marcel Biewendt; visualization, Marcel Biewendt; writing - original draft, Marcel Biewendt; writing - review \& editing, Marcel Biewendt.

\section{References}

1. Amnesty-International. (2019). Amnesty Report 2019. London: Amnesty International. Available at: https://www.amnesty.org/download/Documents/MDE2297582019ENGLISH.PDF.

2. Baráth, L., \& Fertő, I. (2016, April 12). Productivity and Convergence in European Agriculture. Journal of Agricultural Economics, 68(1), 228-248. doi: https://doi.org/10.1111/1477-9552.12157.

3. Beblawi, H., \& Luciani, G. (1987). The Rentier State. Routledge Library Editions: Polictics of the Middle East. doi:978-0-7099-4144-6.

4. Biewendt, M. (2018). The Human Development Index (HDI) as a Reflection of Resource Abundance (using Nigeria and Norway as a case study). Edinburgh: Edinburgh Napier University. (Unpublished).

5. Biewendt, M. (2020). Quantitative Analysis of Nigerian and Norwegian Parameters. Aachen. (Unpublished).

6. Economics, T. (2020, August 3). Trading Economics. Available at: https://tradingeconomics.com/norway/crude-oil-production.

7. Financial-Times. (2020, August 3). Financial Times. Available at: https://www.ft.com/content/3f3f75c49d0c-11e7-8cd4-932067fbf946.

8. Gallardo, G. (2009). The human developmentindex as an effort to measure well-beingin honduras. Korea, Busan: OECD World Forum. Available at: https://www.oecd.org/site/progresskorea/44110008.pdf.

9. Gylfason, T. (2001, May 1). Natural resources, education, and economic development. European Economic Review Vol 45 Issue 4-6, pp. 847-859. doi:https://doi.org/10.1016/S0014-2921(01)00127-1.

10. Halvor Mehlum, K. M. (2006, January). Institutions and the Resource Curse. The Economic Journal; Volume 116, Issue 508, pp. 1-20. doi:https://doi.org/10.1111/j.1468-0297.2006.01045.x.

11. HowMuch. (2020, June 29). HowMuch.Net - Understanding Money. Available at: https://howmuch.net/articles/world-map-of-crude-oil-exports-2016.

12. Mahbub, u. H. (1995). Reflections on Human Development. Oxford: Oxford University Press. doi:9780195101935.

13. Mahdavy, H. (1970). The Patterns and Problems of Economoic Development in Rentier States; the Case of Iran. Available at: https://www.taylorfrancis.com/books/e/9781315000312/ chapters/10.4324/ 978131 5000312-36. 
14. Mohajan, H. K. (2015). Sustainable Development Policy of Global Economy. Premier University, Chittagong, Bangladesh. Bangladesh: Science and Education Publishing. doi:10.12691/env-3-1-3.

15. Norges-Bank. (2020, August 3). Norges Bank Investment Management. Available at: https://www.nbim.no/en/.

16. Odeyeme, O., \& Ogunseitan, O. A. (1985). Petroleum industry and its pollution potential in Nigeria. Oil and Petrochemical Pollution, pp. 223-229. doi: https://doi.org/10.1016/S0143-7127(85)90218-2.

17. Omodadepo, A. O., \& Akanni, O. P. (2013, June 1). Oil Wealth; Meat in Norway, Poison in Nigeria: An Analysis of Human Capital as a Transmission Channel of Resource Curse. Journal of World Economic Research, pp. 39-44. doi:10.11648/j.jwer.20130203.12.

18. OPEC. (2020, July 3). Organisation of the Petroleum Exporting Coutnries. Available at: https://www.opec.org/opec_web/en/about_us/167.htm.

19. Ragnar, T. (2009, July 1). Why do some resource abundant countries succeed while others do not? Oxford Review of Economic Policy, 25(2), 241-256. doi:10.1093/oxrep/grp015.

20. Saunders, M., Lewis, P., \& Thornhill, A. (2009). Research Methods for Business Students (Fith edition). Essex, England: Pearson Education. Available at: https://www.academia.edu/23374295/Research Methods for_Business_Students 5th_Edition.

21. Torvik, R. (2009, July 1). Why do some resource-abundant countries succeed while others do not? Oxford Review of Economic Policy, pp. 241-256. doi:10.1093/oxrep/grp015.

22. Tóth, G., Szigeti, C., \& Szabo, D. R. (2016). Decoupling - shifts in ecological footprint intensity of nations in the last decade. Ecological Indicators, pp. 111-117. doi:10.1016/j.ecolind.2016.07.034.

23. United Nations, D.-P. (2020, June 29). Human Development Reports. Available at: http://hdr.undp.org/en/content/human-development-index-hdi.

24. United Nations, D.-P. (2020, June 28). Human Development Reports. Available at: http://hdr.undp.org/en/countries.

25. Worldbank. (2020, June 28). The World Bank. Retrieved from http://datatopics.worldbank.org/worlddevelopment-indicators/.

26. World's Top Exports. (2020, June 29). World's Top Exports. Available at: http://www.worldstopexports.com/.

\section{Appendix}

\section{Nigeria}

1.

Table 7. Analysis of Variances (ANOVA) for Figure 2. Dataset Nigeria

\begin{tabular}{|l|c|c|c|c|c|}
\hline & DF & Sum SQ & Mean SQ & F-Value & $\operatorname{Pr}(>$ F) \\
\hline HDI Value & 1 & 327.14 & 327.14 & 28.984 & $8.735 \mathrm{e}-06^{3}$ \\
\hline Residuals & 29 & 327.32 & 11.29 & - & - \\
\hline
\end{tabular}

Source: own table. Hypothesis: Share of Resource Rents of GDP does not impact HDI Value.

The null hypothesis that the share of resource-rents has no influence on the nigerian HDI value can be rejected with medium-strong certainty on the basis of the ANOVA performed (see Table 4) with a P-value of 8.735e-06.. Consequently, the share of resource-rents in nigerian GDP thus has an influence on the HDI value and is negatively correlated for the observed timeframe of 15 years.

2.

Table 8. Analysis of Variances (ANOVA) for Figure 3 (linear). Dataset Nigeria

\begin{tabular}{|l|c|c|c|c|c|}
\hline & DF & Sum SQ & Mean SQ & F-Value & $\operatorname{Pr}(>\mathbf{F})$ \\
\hline HDI Value & 1 & 12.161 & 12.161 & 329.1 & $<2 \mathrm{e}-16 * * *$ \\
\hline Residuals & 29 & 1.072 & 0.037 & - & - \\
\hline
\end{tabular}

Source: own table. Hypothesis: GDP per Capita does not impact HDI Value.

${ }^{3}$ Signif. codes: 0 ‘***’ $0.001^{\text {‘** }} 0.01$ ‘*’ 0.05 ‘’ 0.1 ' 1 
The null hypothesis that Nigerian GDP per Capita has no influence on the Nigerian HDI value can be rejected with strong certainty on the basis of the ANOVA performed (see Table 5) with a P-value of $<2 \mathrm{e}-16$. In the case of Nigeria, GDP per Capita thus has an influence on the HDI value and is strongly positively correlated.

3.

Table 9. Analysis of Variances (ANOVA) for Figure 4 (linear). Dataset Nigeria

\begin{tabular}{|l|c|c|c|c|c|}
\hline & DF & Sum SQ & Mean SQ & F-Value & $\operatorname{Pr}(>\mathbf{F})$ \\
\hline GDP per Capita & 1 & 3.724 & 3.724 & 11.36 & $0.00214^{* *}$ \\
\hline Residuals & 29 & 9.509 & 0.328 & - & - \\
\hline
\end{tabular}

Source: own table. Hypothesis: Share of Resource Rents of GDP does not impact GDP per Capita.

The null hypothesis that Nigerian share of resource rents of GDP has no influence on the Nigerian GDP per Capita can be rejected with medium-strong certainty on the basis of the ANOVA performed (see Table 6) with a P-value of 0.00214. In the case of Nigeria, share of resource rents thus has an influence on the GDP per Capita and is negatively correlated.

\section{Norway}

1.

Table 10. Analysis of Variances (ANOVA) for Figure 5 (linear). Dataset Norway

\begin{tabular}{|l|c|c|c|c|c|}
\hline & DF & Sum SQ & Mean SQ & F-Value & $\operatorname{Pr}(>\mathbf{F})$ \\
\hline HDI Value & 1 & 0.0005475 & 0.0005475 & 9.569 & $0.00435 * * 4$ \\
\hline Residuals & 29 & 0.0016594 & 0.0000572 & - & - \\
\hline
\end{tabular}

Source: own table. Hypothesis: Share of Resource Rents of GDP does not impact HDI Value.

The null hypothesis that Norwegian Share of Resource Rents of GDP has no influence on the Norwegian HDI value can be rejected with medium-strong certainty on the basis of the ANOVA performed (see Table 7) with a P-value of 0.00435. In the case of Norway, share of resource rents of GDP thus has a reciprocal influence on the HDI Value and is negatively correlated.

2.

Table 11. Analysis of Variances (ANOVA) for Figure 5 (linear). Dataset Norway

\begin{tabular}{|l|c|c|c|c|c|}
\hline & DF & Sum SQ & Mean SQ & F-Value & $\operatorname{Pr}(>\mathbf{F})$ \\
\hline HDI Value & 1 & 0.0007442 & 0.0007442 & 14.75 & $0.000615 * * *$ \\
\hline Residuals & 29 & 0.0014628 & 0.0000504 & - & - \\
\hline
\end{tabular}

Source: own table. Hypothesis: GDP per Capita does not impact HDI Value.

The null hypothesis that Norwegian GDP per Capita has no influence on the Norwegian HDI value can be rejected with strong certainty on the basis of the ANOVA performed (see Table 8) with a P-value of 0.000615 . In the case of Norway, GDP per Capita thus has a reciprocal influence on the HDI Value and is negatively correlated.

3.

Table 12: Table 11: Analysis of Variances (ANOVA) for Figure 5 (linear). Dataset Norway

\begin{tabular}{|l|c|c|c|c|c|}
\hline & DF & Sum SQ & Mean SQ & F-Value & $\operatorname{Pr}(>$ F $)$ \\
\hline GDP & 1 & 18.62 & 18.619 & 4.741 & $0.0377 *$ \\
\hline Residuals & 29 & 113.89 & 3.927 & - & - \\
\hline
\end{tabular}

Source: own table. Hypothesis: GDP per Capita does not impact Share of Resources.

The null hypothesis that Norwegian share of resources of GDP has no influence on the Norwegian GDP per Capita can be rejected with medium certainty on the basis of the ANOVA performed (see Table 9) with a P-value of 0.0377. In the case of Norway, GDP per Capita thus has a reciprocal influence on the share of resources of GDP and is negatively correlated.

\footnotetext{
${ }^{4}$ Signif. codes: 0 ‘***’ 0.001 '**’ 0.01 '*’ 0.05 ‘, 0.1 ' ${ }^{\prime} 1$
} 